\title{
Reflexões sobre os conflitos entre a manutenção da cultura local rural e o anseio por "modernidades" na vila do distrito de Guaragi, em Ponta Grossa - PR
}

\author{
Reflexiones sobre los conflictos entre la manutención de la \\ cultura local rural y el anhelo por "modernidades" en la villa \\ del distrito de Guaragi, em Ponta Grossa - PR
}

\author{
Reflexions on the conflicts between the maintenance of rural \\ local culture and the desire for"modernity" in the village of the \\ Guaragi district, in Ponta Grossa - PR
}

\author{
Fabelis Manfron Pretto \\ fabelismp@hotmail.com \\ Universidade Estadual de Ponta Grossa \\ Leonel Brizolla Monastirsky \\ leonel@uepg.br \\ Universidade Estadual de Ponta Grossa
}

\begin{abstract}
Resumo: Este artigo apresenta reflexões sobre a relação entre a manutenção da cultura local na vila do distrito de Guaragi, no município de Ponta Grossa - PR, diante das"modernidades" adquiridas por esse espaço, vindas principalmente através dos meios midiáticos e do contato com o urbano. A falta de estudos sobre a temática, a deficiência na organização política do local e a pouca representatividade econômica fazem com que o distrito seja tratado com descaso pelas diversas escalas do poder público e que a população careça de muitosserviços, buscados no espaço urbano. Os traços culturais urbanos chegam à vila e são associados às características rurais expressas nos hábitos e no comportamento da população e compõem a dualidade que expõe o atual contexto social e cultural do distrito.
\end{abstract}

Palavras-chave: Distrito rural. Campo-cidade. Rural-urbano. Cultura.

Resumen: Este artigo presenta reflexiones sobre la relación entre la manutención de la cultura local en la villa del distrito de Guaragi, en el municipio de Ponta Grossa - PR, frente a las "modernidades" adquiridas por ese sitio, venidas principalmente por los medios de comunicación y del contacto con el urbano. La falta de estudios sobre la temática, la deficiencia de la organización política del local y la poca representatividad económica hacen con que el distrito sea tratado con descaso por las diversas escalas del poder público y que la populación careza de diversos servicios, recogidos en el espacio urbano. Los rasgos culturales urbanos llegan a la villa y son asociados a las características rurales expresas en los hábitos y en el comportamiento de la populación y compone la dualidad que expone el actual contexto social y cultural del distrito.

Palabras clave: Distrito rural. Campo-ciudad. Rural-urbano. Cultura. 


\begin{abstract}
This paper presents reflections on the relationship between the District of Guaragi local culture maintenance, in the municipal area of Ponta Grossa - Paraná, and the "advances" acquired by this location, mainly coming from the media and through urban contact. The lack of studies on the subject, the deficiency in the political organization of the location, and the scarce economical representativeness are main reason for the district being treated with contempt by the various scales of government, keeping thepopulation in constant needof many services, sought within the urban space. The urban cultural traits come to the village and are associated with its rural characteristics expressing themselves in habits and behavior of the population, composing, therefore, the duality that exposes the current social and cultural context of the district.
\end{abstract}

Keywords: Rural district. Countryside-city. Rural-urban. Culture.

\title{
INTRODUÇÃO
}

Cidade e campo têm relações sociais distintas, ora complementares ora dicotômicas, e a aproximação entre esses dois espaços, intensificada com o processo de globalização, proporciona características diferenciadas a essas relações.Com a aproximação cada vez maior entre o campo e a cidade, não há como considerar esses dois espaços separados e, para os moradores dos distritos, surgem novas formas de comportamento que ocorrem por influência desse contato - que tanto pode ser harmonioso, quanto conflitante. O campo,que foi por muito tempo considerado espaço subordinado e complementar à cidade, não pode ser analisado como um espaço à parte, mas sim a partir das atuais relações que se estabelecem entre esses dois territórios, com novas configurações e identidades.

O debate entre o que é urbano e rural, cidade ou campo é antigo para diversas áreas do conhecimento. Mascom as rápidas transformações e a articulação intensa entre o território rural e urbano, surgem novas formas de organização espacial: "[...] os limites e distinções entre cidade e campo se esvaecem, à medida que novas formas de assentamento são produzidas e que as relações e articulações entre urbano e rural se acentuam". (SPOSITO; WHITACKER, 2010, p.9).

Dessa forma, alteram-seas relações sociais entre os sujeitos que vivem nesses dois espaços. Percebe-se, no entanto, que há maiores mudanças no cotidiano dos indivíduos que vivem no campo. Segundo Warnier (2000), as culturas não são homogêneas, pois se formam em condições diferentes, lugares e temporalidades distintas; o que as diversifica e lhes dá diferentes valores são singulares, diversos e localizados geograficamente.

A culturaé criada nas ações que ocorrem com os sujeitos sobre um espaço e caracteriza o conjunto dos conhecimentos, práticas e ações dos sujeitos. Está sempre em construção, alterada pelo contato com novas culturas e também pelas novasnecessidades dos indivíduos que se apresentam com o passar do tempo. Como resultado das relações sociais, a cultura é formada na relação entre indivíduos com personalidades e contextos sociais e históricos diferentes. 
O contato entre diferentes grupos, diferentes indivíduos e as próprias mudanças internas dentro de um sistema cultural são fatores que possibilitam o constante processo de construção, reconstrução e renovação de uma cultura. Esse movimento de aproximação entre indivíduos leva traços culturais de um grupo a outro. A aculturação caracteriza essa troca de informações culturais que modificam a cultura dos grupos envolvidos. Não há, todavia, a eliminação das culturas relacionadas, pois há um movimento de troca, que pode ser desigual, mas não existindo um grupo que apenas recebe e outro que apenas passa a informação.

As culturassão resultado de relações sociais históricas e se desenvolvem numa sociedade onde as classes sociais sempre existiram, portanto, resultam em hierarquias culturais. (CUCHE, 1999). Há grupos e indivíduos que ocupam posição superior social, política e econômica, e são produtores da cultura dominante, imposta aos dominados, que podem ou não aceitá-la. A cultura produzida nas cidades é por vezes vista como superior e melhor que ado campo, denotando fascínio sobre os moradores da zona rural. Porém, nos grupos dominados há uma efervescência de criatividade, e os signos e símbolos da cultura dominante são reinterpretados.

Com a globalização, as tecnologias se difundem mais rapidamente e com maior abrangência, atingindo muitos indivíduos e praticamente todos os lugares, contudo, não de forma homogênea. Penetram o cotidiano dos indivíduos e alteram sua forma de agir e pensar, dando novo significado aos espaços, mas, ao mesmo tempo, reafirmando seus valores - como é possível perceber nas atuais configurações das relações entre cidade e campo.

A identidade do sujeito, construída constantemente nas trocas sociais entre os indivíduos, era anteriormente erguidasobre bases estáveis, num processo de mudanças lentas; já na contemporaneidade é fluida, dinâmica, e os indivíduos têm de se adaptar a um processo de identificação rápido, dependente da situação com a qual é confrontado. Assim, ao receber constantemente novas informações, novos sistemas de significações e representações culturais, o indivíduo é confrontado comuma variedade de novas identidades, e pode ora identificar-se mais com uma ora com outra, fato esse que pode ser intuído na observação do cotidiano dos moradores das vilas de distritos, que ora se adaptam ao rural ora ao urbano.

As modernidades - produtos eserviços que apresentam simbologia de inovação tecnológica e refletem as mudanças constantes, rápidas e permanentes da sociedade capitalista industrial e que são adquiridas ou se aproximam dos moradores do campo -vão se instalando nos diversos lugares, sendo levadas principalmente pela mídia, pela facilidade de acesso e pelo aumento das necessidades de consumo de produtos e bens não encontrados no lugar de vivência. Na contemporaneidade, com o acessoàs redes-infraestrutura que permite troca de informação, produtos, energia e também onde ocorrem trocas de mensagens, valores, pensamentos -as trocas são dinamizadas, a informação circula de maneira rápida e permanente, sendo quase instantânea e chegando a praticamente todos os lugares.

Alguns trabalhos elaborados até o momento auxiliaram na construção da pesquisa, como o de Silma Rabelo Montes, do estado de Minas Gerais, que produziu o trabalho 
intitulado "Entre o campo e a cidade: As territorialidades do distrito de Tapuirama (Uberlândia - MG) - 1975 a 2005", trazendo considerações sobre a relação histórica da territorialidade entre o distrito de Tapuirama e as cidades vizinhas.

Na produção estadual tem-se o trabalho de Marcel Saab R. Manaia, intitulado “ $A$ geografia dos distritos rurais de Paiquerê e Warta, Londrina-Paraná" , no qualhá uma discussão sobre a formação dos distritos no contexto da região do município de Londrina. Quanto aos distritos do município de Ponta Grossa, Luciane Bauchrowitz apresentou o trabalho "Caracterização dos distritos de Guaragi e Uvaia: uma contribuição para o planejamento distrital do Poder Público do município de Ponta Grossa (PR)", em quesão apresentadas as principais características socioeconômicas desses distritos e os projetos elaborados pelo Poder Público municipal para esses espaços. Também a dissertação de Vanessa Marques Barreto, intitulada "As especificidades do processo de formação histórico-geográfico do distrito de Guaragi - Ponta Grossa (PR)", na quala autora faz a reconstituição histórica da formação do distrito e como se estabelecem as relações deste com o espaço no presente.

Com as mudanças na relação entre campo e cidade, alguns espaços podem ser considerados híbridos culturais, ora identificando-se mais com a cultura rural, e com otempo mais lento, ora com a cultura urbana, e com o tempo rápido, e, frequentemente, com o desejo deadquirir certos bens e também novos hábitos. Dessa forma, esse trabalho analisa essa relação dialética entre os hábitos locais e o anseio dos moradores dos distritos rurais em adquirirem serviços e produtos que não são encontrados na zona rural.

A pesquisa foi construída na perspectiva de contribuir com o desenvolvimento da discussão teóricaacerca dos distritos rurais, onde a população residente na(s) vila(s) é considerada pelo Instituto Brasileiro de Geografia e Estatística (IBGE) como parte integrante da população urbana - mesmo não se identificando como tal e mantendo vínculos estreitos com o modo de vida rural. Também se busca oferecer um instrumento para o Poder Público atender de maneira adequada às necessidades dos moradores da vila do distrito, onde existem diversas especificidades que devem ser consideradas no momento da formulação de projetos, em razãodessa característica da existência de traços urbanos e rurais no cotidiano dos moradores.

O município de Ponta Grossa abrange cinco distritos, segundo o IBGE: o distrito sede,Piriquitos, que está vinculado à malha urbana,Itaiacóca, Uvaia e Guaragi, que estão afastados do perímetro urbano. Guaragi é localizado a $32 \mathrm{~km}$ da zona urbana de Ponta Grossa, com acesso pelas rodovias PR 151 e PR 438. Conta com uma população de aproximadamente 2.936 habitantes, sendo, destes, 1.241 moradores da vila e 1.695 moradores da área rural. (IBGE - Censo 2010).

Para a elaboração desse trabalho utilizou-se a revisão bibliográfica para os conceitos referentes à pesquisa, sendo o tema "distritos rurais" ainda pouco abordado pelas diversas áreas de produção do conhecimento. Utilizaram-se também dados referentes ao Censo de 2010 (IBGE).Para identificar os traços culturais e a influência das modernidades na (re)criação ou negação da sua cultura local, no mês de outubro de 2010, foi realizada uma pesquisa de campo com quarenta moradores da vila do distrito de Guaragi, que foram questionados sobre seus hábitos e costumes. Escolhidos de maneira aleatória, 
buscou-se contemplar diversos pontos na vila entrevistando-se os moradores em suas casas. O questionário foi elaborado por um grupo de pesquisas sobre distritos rurais da Universidade Estadual de Ponta Grossa, com o intuito de possibilitar o entendimento de traços culturais dos moradores da vila, auxiliando na compreensão da cultura local e abordando temas como política, economia, infraestrutura local, hábitos diários, acesso aos centros urbanos e meios de informação.

\section{CONCEITOS E REFLEXÕES}

A cultura pode ser vista com fundamental importância para tratar da relação do homem com o meio e das relações sociais que se estabelecem no espaço geográfico. Através das relações sociais mantidas pelos indivíduos e o contexto histórico, político e econômico que vivenciam, a cultura deve ser analisada como em constante transformação, moldando-se as necessidades atuais dos atores sociais, agregando fatores, substituindo-os, incorporando as novidades, refutando-as, criando e recriando significados para as coisas e espaços:

A cultura é indispensável ao indivíduo no plano de sua existência material. Ela permite sua inserção no tecido social. Dá uma significação a sua existência e a dos seres que o circundam e formam a sociedade da qual se sente membro. Ela não desempenha o mesmo papel nos diversos momentos da vida. (CLAVAL, 2007, p. 89).

A cultura é uma das formas pela qual o sujeito apropria-se do espaço, estabelecendo sobre ele relações sentimentais e políticas. Os moradores da vila do distrito de Guaragi têm laços de afetividade com o local onde vivem. Essa identificação dos sujeitos com os locais onde vivem pressupõe uma ligação com a história do lugar, dando a ele significações especiais, o sentimento de pertença a esse espaço e o compromisso com sua manutenção e melhoria. Nos seus hábitos o indivíduo expressa a forma como vive, pensa e interage com a sociedade, e é possível identificar a herança cultural que trás em si. Formam-se então as realidades e os signos criados para expressão dessa cultura:

A cultura é a soma dos comportamentos, dos saberes, das técnicas, dos conhecimentos e dos valores acumulados pelos indivíduos durante suas vidas e, em uma outra escala, pelo conjunto dos grupos de que fazem parte. A cultura é herança transmitida de uma geração a outra. Ela tem suas raízes num passado longínquo, que mergulha no território onde seus mortos são enterrados e onde seus deuses se manifestaram. Não é portanto um conjunto fechado e imutável de técnicas e de comportamentos. Os contatos entre povos de diferentes culturas são algumas vezes conflitantes, mas constituem uma fonte de enriquecimento mútuo. A cultura transforma-se, também, sob o efeito das iniciativas ou das inovações que florescem no seu seio. (CLAVAL, 2007, p. 63).

Por viver em um mesmo espaço, os indivíduos tendem a apresentar os mesmos rituais cotidianos, valores semelhantes e um mesmo sentimento de apego e pertencimento 
a determinado espaço, compartilhando das mesmas formas de vestir, dos mesmos horários, da mesma forma de alimentação, enfim, os mesmos hábitos. O conjunto de representações, conhecimentos, atitudes e práticas são transmitidos aos descendentes.

Contudo, a partir da sua história, do seu diaadia, das suas experiências, o indivíduo agrega à sua cultura novidades. A cultura proporciona também, na história do sujeito, uma carga emotiva e, como afirma Santos (2006, p. 52-53): “[...] existe um agir simbólico, que não é regulado por cálculo e compreende formas afetivas, emotivas, rituais, determinadas pelos modelos gerais de significação e de representação", e Claval (2007, p. 81): "Cada cultura caracteriza-se por um sistema original de representações e de construções intelectuais. Isto não ocorre sem influência sobre a afetividade e sobre a atividade."

Por coabitar num mesmo espaço e pela divisão dos mesmos códigos, os moradores da vila de Guaragi criaram vínculos de amizade e participação na vida social do seu território que ligam as pessoas não somente umas às outras, mas também, através de suas memórias, a um lugar repleto de sentimento de pertencimento, de apego, onde os membros desse grupo tiveram, em algum momento de suas vidas, experiências ocorridas num mesmo espaço, como por exemplo casarem-se na mesma igreja, organizarem uma festa popular, frequentarem a mesma escola e iremaos bailes no clube da vila, etc.

Como há uma diversidade de grupos culturais, o indivíduo sente a necessidade de pertencer a um grupo, e isso se dá através da identidade, ou identificação - já que é um processo dinâmico, em constante mudança -, com um grupo. Formada num jogo de lutas, a identidade é que diferencia os grupos, os indivíduos, que podem adotar uma identidade sólida de poucas mudanças, ou identidades fragmentadas que se adaptema rápidas mudanças do sistema social.

A identidade é o que liga o indivíduo a um grupo social, e sofre influência desse grupo e diferencia grupos distintos; a identidade pode mudar segundo o contexto, assumindo múltiplas faces. Quando a identidade é atrelada a uma cultura, ela impregna no sujeito características únicas e próprias dessa vinculação. (WARNIER, 2000).

Para Cuche (1999), a identidade é uma forma de vinculação do sujeito com o grupo a que pertence, e é caracterizada por um conjunto de vinculação as diferentes classes a que o indivíduo pertence - sexo, gênero, idade, nação, classe social -, além de permitir que ele se localize dentro de um sistema social e seja reconhecido como pertencente a ele. Seria assim, uma forma de diferenciar um grupo de outro. Todavia, essa identidade está em constante construção e reconstrução, e seria apropriado, portanto, utilizar o termo identificação.

Formada pela relação do sujeito com suas próprias experiências e com o contato com o mundo e com a sociedade, a identidade, como afirma Hall (2006, p. 11), "[...] é formada na interação do eu e a sociedade. Sujeito com núcleo interior "eu real" e modificado no contato com [...] os mundos culturais "exteriores" e as identidades que esses mundos oferecem".

O viver diário, a construção de sua história, o sentimento de pertencimento ao lugar eo viver num grupo fazem com que o sujeito tenha uma identificação, como é visto na vila do distrito. A identidade é formada entre os contrastes da sociedade àqual o indivíduo pertence e o das suas experiências, e para Claval (2007, p. 98) "A identidade é 
de uma só vez individual e coletiva". O sentimento de identidade torna possível aos indivíduos que pertencem a um grupo manter suas especificidadesao entrar em contato com membros de outros grupos culturais -no caso dos moradores da vila, a manutenção das características rurais, diante do contato com o urbano -, pois o sujeito expressa através da sua identidade a sua própria pessoa, construída com base na vivência em determinado espaço e com os demais indivíduos da cultura a que pertence, a conformidade com o grupo do qual participa e o respeito por sentimentos e comportamentos comuns que o "costuram" à estrutura sociocultural, ao mundo real.

Para Corrêa (2003), é necessário compreender os significados dos saberes, técnicas e crenças de um grupo, pois estes nas representações e práticas dão sentido à vida de um grupo. Segundo esse autor, os sistemas de significados se concretizam na organização social e espacial, estruturam e modelam as relações sociais, e ainda a forma de experiência, entendimento e interpretação do espaço. Para Corrêa, os grupos sociais atribuem significados aos objetos e ações, segundo o espaço-temporalidade, em seus processos de existência. Esse conjunto de significados, de técnicas e saberes forma a cultura.

Os moradores da vila do distrito de Guaragi também apresentam a sua cultura e uma identificação. Contudo, a identidade pode ser por vezes questionada, pois não é imutável. Pode alterar-se segundo as necessidades que vão surgindo com as novidades que chegam aos indivíduos, sendo adaptada, recriada, mantida em certos aspectos, de acordo com as exigênciasdas novas configurações econômicas, políticas e socioculturais. A identidade pode resistir ao tempo, mas recebe constantemente a carga de novas motivações que chegam ao sujeito.

O espaço habitado e vivido pelo sujeito sempre esteve intimamente ligado com a formação da sua identidade cultural. Para Claval (2007, p. 183) "[...] as culturas podem coabitar nos mesmos lugares, interpenetrarem-se e cruzarem-se sem perder suas especificidades." É assim que se pode perceber a cultura do morador da vila do distrito.

O espaço onde se desenvolve uma identificação e que é apropriado por um grupo de atores sociais, tornando-se palco de sua produção e experiências, adquire um valor de uso, dado por esse grupo que sobre ele desenvolve controle simbólico. Entre as relações que se estabelecem em um espaço, as de poder são muito significativas. Um espaço apropriado por sujeitos que dão a ele uma série de significações, dotado de relações de poder, é um território.

O território é um espaço com conotação material e simbólica, apropriado por sujeitos que dão a ele uma série de significações; carregado de poderes simbólicos e políticos, é ainda permeado por relações econômicas. Pode ser um espaço fragmentado que une campo e cidade, formando territorialidades. Aterritorialização é um processo de domínio de poderes e apropriação simbólico-cultural dos territórios, que pode se dar através de imagens e mitos e se forma quando o indivíduo se sente parte de um território. (MONTES, 2006).

A condição técnico-informacional de um local influencia a formação da identidade cultural dos indivíduos e também a representatividade que um local apresenta. Espaços com maior arcabouço técnico-científico têm maior poder. A cidade é o espaço que concentra aspectos econômicos, sociais, políticos, culturais e simbólicos com maior densidade, 
apresentando-se com certa hegemonia. Contudo, o dinamismo social e econômico vem trazendo novas formas de configuração territorial. Com essa nova configuração ocorre uma revalorização do campo.

O território pode ainda ser visto por determinadas formas de percepção do espaço pelas estruturas físicas que apresentam e marcam o cotidiano das pessoas; marcos físicos e simbólicos que estabelecem relações de poder e tramas históricas sobre o espaço:

[...] o território aparece, assim, como o receptáculo da memória coletiva dos indivíduos, das famílias, dos clãs, das tribos, das organizações e das comunidades. Esta herança deve servir de base ao analista, porque não se pode compreender a situação atual de um território sem se referir a seu passado e não se pode compreender a realidade atual de um país sem se referir ao passado de seus territórios. (PROULX, 1997, apud WANDERLEY, 2000, p. 117).

Os distritos são espaços interescalares, locais de limite e encontro entre a cidade e o campo, entre o urbano e o rural. Na vila do distrito de Guaragi, ocorre a interação entre o presente e o passado, entre o moderno e o tradicional. No Brasil, o termo distrito é utilizado para designar uma divisão territorial dos municípios. São criados com a finalidade de que o Poder Público municipal possa melhor atender as necessidades dos moradores desses locais. Estão subordinados, portanto, ao poder do município. A sede dos distritos são as vilas, onde geralmente há uma concentração de moradores, considerados pelo IBGE moradores urbanos, independentementeda sua identificação como urbanos ou rurais.

O debate entre o que é cidade e campo, e urbano ou rural estámuito presente nas ciências. Contudo, com as mudanças ocorridas nas formas de organização do espaço nas últimas décadas, novas considerações têm sido tecidas sobre esses temas. Para o IBGE, um município é formado pelo conjunto de zona rural e zona urbana, sendo considerados rurais toda a população e os domicílios encontrados fora do perímetro urbano, e urbanos, as pessoas e os domicílios que se encontram no perímetro urbano, as vilas (sedes de distrito) e as áreas urbanas isoladas.

Segundo Sposito e Whitacker (2010), com as rápidas transformações na forma de organização espacial, novas formas de assentamento humano são produzidas, articulando-se de forma diferente o rural e o urbano: “[...] os limites e distinções entre cidade e campo se esvaecem, à medida que novas formas de assentamento são produzidas e que as relações e articulações entre urbano e rural se acentuam". (SPOSITO; WHITACKER, 2010, p.9).

A cidade pode ser compreendida como centro urbano, como uma materialização arquitetônica, ou ainda como lugar que concentra a sede do poder produtivo, religioso, político, entre outros. A cidade deve ser abordada:

[...] como meio, condição e produto da sociedade, tendo em suas formas a manifestação concreta das contradições sociais presentes e sendo seu conteúdo a expressão dessas contradições. A concepção do urbano extrapola a própria cidade, consubstanciando-se na relação cidade-campo, tendo na divisão técnica, social e territorial do trabalho a sua base. (BERNARDELLI, 2010, p. 33). 
Na cidade o tempo é mais rápido, e as pessoas têm suas vidas cronometradas. Segundo Santos (2006), cada lugar pode ser distinguido pela sua diferença de temporalidades, cada tempo ganha sua concretude com a interpretação na vida ativa dos agentes sociais, e as temporalidades caracterizam a forma de ocupação e vivência do espaço de um determinado lugar. O tempo do campo é tido como mais lento. O campo foi por muito tempo considerado espaço de atraso, arcaico, onde as condições mínimas de vida são conseguidas através de grande esforço. Também considerado espaço de tranquilidade, de contato com a terra, de paisagens mais naturais.

Contudo, o campo passou a desenvolver atividades que anteriormente eram típicas das cidades - por intermédio do maior contato com informações, da proximidade geográfica desses espaços e da facilidade de acesso através do desenvolvimento do sistema de transportes -, e bens de consumo e símbolos urbanos foram integrados ao cotidiano dos moradores do campo, principalmente quanto às atividades de lazer, prestação de serviços mais especializados e mercadorias, dando ao campo características urbanas e de modernização.

Campo e cidade são interdependentes, e cada vez mais o urbano "invade" o rural. Campo e cidade são territórios que mantêm relações técnicas, históricas e culturais e sofrem influência de forças políticas, econômicas e das forças hegemônicas globais e locais. O rural e o urbano podem ainda ser considerados como modos de vida. Porém, o rural extrapola o campo, e o urbano extrapola a cidade. Para Endlich (2010, p. 19) "O rural e o urbano [...] são dimensões sociais produzidas no decorrer da história", e são incorporados ao sistema de vida do sujeito. Rural e urbano podem ser considerados modos de vida, formas de consumo e apropriação do espaço.

Segundo Endlich (2010) o modo de vida urbano se concretiza além da cidade, pois se consolida pelo encantamento que as cidades exercem e sua influência pelo poder daspersonalidades einstituições e chega ao campo pelos meios de comunicação e transporte. O modo de vida urbano se aproxima intensamente do campo e o despoja de determinados elementos que lhe eram característicos ou lhe atribui novos valores e funções, sendo que o modo de vida rural se adapta a essas novidades ou as adapta a seu modo.Portanto, o maior contato entre rural e urbano, entre cidade e campo, não determina que esses espaços passem a ser iguais, ou que o urbano aos poucos acabe com o rural:

Embora transformações apontem aparentemente para a homogeneização dos espaços, em virtude da difusão de características comuns, a intensificação das relações se estabelece justamente pela manutenção das peculiaridades. Os espaços ampliam suas inter-relações, porque as diferenças existentes em cada um deles favorecem a busca pelo outro como tentativa de suprimir possíveis ausências. (BAGLI, 2010, p. 82).

O modo de vida urbano exerce um tipo de encantamento sobre os moradores do campo, e se apresenta a eles de diversas maneiras e por diferentes motivações.Segundo Endlich (2010, p. 20): “Assim, o modo de vida urbano estende-se até os limites geográficos alcançados pelos interesses, ações e conteúdos presentes nas cidades". No distrito de Guaragi, os moradores anseiam pelo consumo do modo de vida urbano, dos símbolos 
que exercem encantamento sobre esses sujeitos, pois representam para eles ascensão econômica e melhoria de vida, além das facilidades e comodismos que muitos dos bens materiais trazem ao diaadia dos moradores:

A realização da produção se dá só através do consumo e se realiza na cidade, embora o consumo possa ser também o da cidade, através de signos e símbolos urbanos e o consumo também se traduza em desejos e necessidades, sendo que o primeiro é, ideologicamente, travestido no segundo. (WHITACKER, 2010, p. 150).

Para Bernardelli (2010, p. 48), “A vida rural é associada, geralmente, com uma expressiva valorização da comunidade, valores de vida da família e também ao papel importante da religião". No distrito muitos costumes de socialização são mantidos, como as festas religiosas, as conversas no fim da tarde acompanhadas da roda de chimarrão, das visitas aos familiares nos finais de semana e das refeições feitas com a família reunida:

[...] o "rural" é um modo particular de utilização do espaço e de vida social. Seu estudo supõe, portanto, a compreensão dos contornos, das especificidades e das representações deste espaço rural, entendido, ao mesmo tempo, como espaço físico (referência à ocupação do território e aos seus símbolos), lugar onde se vive (particularidades do modo de vida e referência identitária) e lugar de onde se vê e se vive o mundo (a cidadania do homem rural e sua inserção nas esferas mais amplas da sociedade). (KAISER,1990 p. 13, citado por WANDERLEY, 2000, p. 88).

Porém, o rural não pode ser visto como oposição, mas sim na relação que tem com a cidade, e não pode ser mais explicado somente pela atividade agrícola que gera um maior contato com a terra, já que surgem cada vez mais no campo profissões e atividades que são tipicamente urbanas. A ruralidade seria a forma de expressão da identidade rural, representando quais hábitos, costumes, sistemas de valores e formas de vivência cotidiana estariam atrelados à formação da identidade do sujeito rural.

Quando os moradores do campo entram em contato com o estilo de vida urbano, podem permitir que alguns ou muitos símbolos, valores, hábitos e rituais da vida urbana passem a fazer parte do seu cotidiano, mas são mantidas as especificidades rurais, características do seu modo de vida.A relação que se estabelece entre o urbano e o rural pode resultar em novas práticas e representações para todos os sujeitos que vivenciam esse contato, sobretudo no que diz respeito às formas de ocupar e viver o espaço, as temporalidades, as condições e características do trabalho, os valores familiares.

Com o contato entre a cidade e o campo, intensificado com o acesso facilitado pela evolução dos meios de transporte e acesso aos meios de telecomunicação, o consumo de bens e serviços urbanos pela população rural aumentou, e através da difusão de técnicas e de hábitos de origem urbana, a distinção entre campo e cidade tem sido reduzida gradativamente nas últimas décadas.

Como a cultura não é algo permanente e imutável, durante a história de uma sociedade ela será colocada, por diversas vezes,diante de novas culturas, e as identidades 
culturais dos sujeitos poderão receber influência desses contatos. Na vila do distrito de Guaragi se percebe as mudanças que são inseridas no cotidiano e, portanto, na cultura do morador da vila, quando hábitos e costumes são agregados ao diaadia e alterados por influência do contato com o urbano:

A emergência de uma identidade cultural é um produto da história e o grupo que daí resulta pode ser um dia questionado e atravessado por novas linhas de cisão. As configurações culturais não ficam congeladas. Há momentos em que os valores até então aceitos são criticados, porque não correspondem mais aos imperativos da vida econômica ou às necessidades da vida de relações. As técnicas mudaram. Os valores tradicionais convinham bem a um universo rural, onde a vida local predominava. Para estruturar as sociedades ampliadas, fazem-se necessárias outras motivações. (CLAVAL, 2007, p. 183-184).

Porém, nem todas as novidades que chegam são agregadas àcultura já existente. Algumas são aceitas de maneira integral, outras são reformuladas, ou readequadas às necessidades do grupo naquele momento e segundo seus desejos:

A cada momento, cada lugar recebe determinados vetores e deixa de acolher muitos outros. É assim que se forma e mantém a sua individualidade. O movimento do espaço é resultante desde movimento dos lugares. Visto pela ótica do espaço como um todo, esse movimento dos lugares é discreto, heterogêneo e conjunto, "desigual e combinado". (SANTOS, 2006, p. 87).

Haveria assim uma continuidade entre os espaços rurais e urbanos, sendo que nas últimas décadas as disparidades entre eles foram reduzidas. Assim, as diferenças são mantidas e é possível reconhecer que há um reforço nas identidades diferenciadas para esses dois espaços e que há um sentimento de pertencimento ao lugar, para o morador urbano e para o rural. É sobre essa base que a cultura afirmaria a existência de uma identidade rural baseada no sentimento de pertença a um lugar:

Nessa perspectiva, as transformações na comunidade rural provocadas pela intensificação das trocas com o mundo urbano (pessoais, simbólicas, materiais...) não resultam, necessariamente, na descaracterização de seu sistema social e cultural como os adeptos da abordagem adaptacionista interpretavam.Mudanças dehábitos, costumes, e mesmo de percepção de mundo, ocorrem de maneira irregular, com graus e conteúdos diversificado, segundo os interesses e a posição social dos atores, mas isso não implica uma ruptura decisiva no tempo nem no conjunto do sistema social. (CARNEIRO, 1998, p. 58).

Com o estabelecimento de uma cultura de massa, o processo de globalização -em queas distâncias ficam mais curtas, graças ao desenvolvimento de um sistema de telecomunicações de alta tecnologia e da melhoria dos sistemas de transporte -cria uma homogeneização cultural, mas também o reforço das identidades locais.

Outra característica da globalização, que também pode ser vinculada à identidade partilhada, é o querer consumir os mesmos espaços, como o campo, que está sendo 
transformado em espaço de consumo, que deve ser preservado com todas as suas características e peculiaridades, considerado ideal para se viver, pela tranquilidade e pelos sentimentos de bucolismo que causa. Isso mostra o caráter da globalização de criação de nichos de mercado e da especialização de espaços, que valoriza características locais, ou seja, a forma como um lugar se diferencia dos demais, seja pelo sentimento que é capaz de causar, sejapelo consumo da cultura que pode ser feito nesse lugar. Há, portanto, um reforço das identidades locais graças à globalização.

Contudo, a globalização não atinge de maneira igualitária todos os lugares, chegando de maneira diferente à população das diversas regiões e estratos sociais. Isso também é observado na relação campo-cidade. Apesar de haver certa homogeneização desses dois espaços, não se pode ignorar que grande parte da população que reside no meio rural ainda constitui uma parcela desprovida de condições de acesso a muitos tipos de bens de consumo material e não material:

O processo de "modernização rural", como foi visto, é extremamente complexo e não pode ser entendido simplesmente como o "fim da agricultura" ou o "fim do rural". A modernização da sociedade nos espaços locais/rurais tem como fundamento a crescente "paridade social", isto é, a similitude entre as condições de vida das populações que vivem nas cidades e no meio rural e a também crescente disponibilidade, no meio rural, daquilo que ainda é definido como o padrão de "conforto urbano". (WANDERLEY, 2000, p. 134).

A globalização pode criar novas identidades, novas posições de identificação. Segundo Hall (2006), a fragmentação dos códigos culturais, a multiplicidade de estilos, a ênfase em tudo que é transitório, na diferença e no pluralismo cultural em escala global é o pós-moderno global:

Em toda a parte, estão emergindo identidades culturais que não são fixas, mas que estão suspensas, em transição, entre diferentes posições; que retiram seus recursos, ao mesmo tempo, de diferentes tradições culturais; e que são o produto desses complicados cruzamentos e misturas culturais que são cada vez mais comuns num mundo globalizado. (HALL, 2006, p. 88).

Para Hall (2006) na modernidade tardia, outro tipo de identificação que os indivíduos podem ter são as culturas híbridas. Os integrantes dessa cultura híbrida devem acostumar-se a ter ao menos duas identidades, levando consigo os seus traços culturais, mas adaptando-se as novas cargas que recebem todos os dias. A vila do distrito representa essa sensibilidade na descontinuidade da fronteira entre a cidade e o campo, entre o urbano e rural, pois nela existem características físicas e culturais do meio rural, como as hortas e pomares cultivados pelos moradores e os espaços destinados à criação de animais para consumo - o que confere àvila sons, sensações, cores, formas, distribuição de espaços caracteristicamente rurais -e o desejo, por parte dos moradores, de que exista nesse espaço estruturas como academia de ginástica, internet, lanhouse, shopping, entre 
outros, características simbólicas das cidades. Algumas especificidades devem ser consideradas quando se fala em distritos rurais:

[...] os distritos devem ser pensados em sua totalidade, o que envolve as relações econômicas, políticas e culturais presentes nesses locais e as relações com as sedes municipais, não sendo entendidos como oposição campo-cidade, mas sim na sua relação com a cidade. (BARRETO, 2011, p. 16).

Um amplo contexto de análise deve ser feito para compreender os distritos rurais, não somente em suas relações com as cidades próximas e a sede municipal, como nas relações internas desses espaços, pois os distritos são espaços de ligação entre cidade e campo, exprimindo, assim, essas duas identidades culturais, que devem ser consideradas para abranger toda a complexidade de relações nesses locais.

A cidade como espaço que concentra as atividades políticas, econômicas, culturais, religiosas, e denota o poder das instituições e das personalidades, exerce um encantamento sobre os indivíduos. (ENDLICH, 2010). Na cidade é possível atender àsnecessidades e aos desejos de consumo, como também do modo de vida urbano, do qualprovém muitos dos anseios de consumo da população rural. Muitas novidades adquiridas pelos moradores do campo -que fazem parte da rotina dos moradores urbanos -assumem significado de melhoria na condição econômica do sujeito e na sua qualidade de vida.

\section{A VILA DE GUARAGI: ENTRE O RURAL E O URBANO}

No distrito a estrutura comercial e de prestação de serviços é pouco variada. Existem apenas algumas mercearias, lanchonetes, lojas de utensílios e roupas, e um posto de combustível. Apesar de muitos moradores da vila do distrito manterem o hábito de cultivar seus alimentos e criar os animais para consumo, muitos deixaram de lado esses costumes mais próximos do modo de vida rural. A proximidade com os mercados e a facilidade na aquisição de produtos industrializados aumentaram a necessidade de comprar o que antes era obtido pela fabricação caseira. Contudo, segundo os moradores, os preços praticados pelos comerciantes locais são altos e incompatíveis com a renda da população, já que muitos moradores retiram o ganho do trabalho em fazendas locais ou dos empregos nas cidades vizinhas. As compras feitas na vila são apenas para atender às necessidades urgentes. Os serviços prestados na área de saúde também são de atendimento básico, tanto médico quanto odontológico, e não há serviço bancário na vila.

As cidades vizinhas são procuradas, sobretudo, para fazer as compras de mantimentos para o mês, em busca de serviços bancários, e para atendimentos especializados ou de maior urgência na área de saúde. Os moradores também frequentam templos religiosos nas cidades vizinhas (novenas e celebrações especiais). Algumas atividades de lazer são desenvolvidas na cidade, já que na vila não existem muitas opções para entretenimento da população nos momentos de folga. 
Vários jovens buscam fora da vila prestações de serviços na área educacional. Muitos moram na cidade de Ponta Grossa para estudar ou se deslocam todos os dias para frequentar cursos profissionalizantes, técnicos e ensino superior. Os postos de trabalho existentes no local também não atendem àdemanda da população, e muitos moradores se deslocam até as cidades vizinhas para trabalhar, sobretudo as mulheres - muitas mães deixam os filhos com familiares, pois na vila não há creche. Os homens, em suamaioria, trabalham em fazendas nos arredores da vila, em outros municípios ou em outra região de Ponta Grossa.

É o contingente policial da cidade de Ponta Grossa que presta o atendimento de segurança aos moradores da vila, pois no local existe apenas um posto policial, masse encontra desativado. Quando há ocorrências, a população aciona o serviço, e os policiais se deslocam até o distrito. Os moradores mais antigos atribuem à culpa do aumento da criminalidade aos moradores procedentes de outros locais, que moram há pouco tempo na vila, à facilidade de acesso à cidade - onde os jovens compram drogas para revender no distrito, segundo os moradores -, e porque a vila écaminho de acesso a outros municípios.

Um dos entraves para que as necessidades dos moradores da vila sejam atendidas é a falta de representatividade e organização política do local. As especificidades desses espaços são desconhecidas do poder público e a falta desse contato político impede o reconhecimento das necessidades locais, desde as mais urgentes e específicas - como saúde, segurança, educação e trabalho - até o lazer, e a infraestrutura necessária para o desenvolvimento tecnológico e econômico da vila. As mudanças devem ocorrer, entretanto, sem afetar o modo de vida rural tão prezado pelos moradores, que preserva a tranquilidade da vida no campo.

Os contatos que se estabelecem com a cidade ocorremde forma generalizada para atender àsnecessidades que não são supridas na vila, sejam elas de consumo de bens ou serviços. Grande parte do consumo se deve àmelhoria nas condições de vida da população, que pode ter acesso a bens que antes eram considerados como padrão de conforto urbano e estão cada vez mais disponíveisàpopulação rural.

Quanto àsua autoidentificação, os residentes da vila se definem como rurais, mas não sabem dizer por que assim se definem, pois têm seu cotidiano rural invadido gradativamente pelo modo de vida urbano, trazido, sobretudo, pelos meios de comunicação de massa. O espaço da vila ganha gradualmente característica de um espaço transitório entre o rural e o urbano, preservando atributos rurais e recebendo as novidades do espaço urbano. Assim, a vila do distrito pode ser considerada um espaço de transição; a identidade dos indivíduos que moram na vila também pode ser considerada em transição, ocupando diferentes posições: ora são predominantemente rurais, ora urbanas, retirando seus traços das diferentes culturas com que têm contato.

Nas relações sociais que estabelece com o meio onde vive e com as sociedades com as quais interage, recebendo continuamente a influência de fatores externos - provenientes, sobretudo, do contato com o urbano e com as mídias -, o morador da vila não perde suas características rurais. Apesar da intensificação das trocas com o urbano - sejam símbolos, 
produtos ou pensamentos -, a coletividade dos habitantes da vila do distrito de Guaragi não passa por um processo de desestruturação do sistema sociocultural rural, pois as mudanças não ocorrem de maneira homogênea para as pessoas e nem mesmo na vila:

As novas experiências engendradas contribuíram para criar uma diversidade social e cultural que é também condição de existência da sociedade na medida em que alimenta as trocas ao enriquecer os bens (culturais e simbólicos) e ampliar a rede de relações sociais. A heterogeneidade social, ainda que produza uma situação de tensão, não provoca obrigatoriamente a descaracterização da cultura local. (CARNEIRO, 1998, p. 58).

Nessa integração, o modo de vida rural dos moradores sofre um processo de reestruturação nos âmbitos social, econômico e cultural. A afirmação do modo de vida rural na vila pode ser percebida quando citadinos vão para o distrito procurando vivenciar as experiências bucólicas e as práticas do modo de vida rural, e consumir bens simbólicos e materiais que são considerados rurais. Mas essas mesmas pessoas não se abstêm dos confortos da cidade, como infraestrutura, aparelhos eletrodomésticos, mobílias e víveres que tragam mais conforto a sua estadia no distrito e estão relacionadas com a vida urbana. Contudo, apesar de preservar um conjunto de particularidades aprazíveis, o campo não deve ser fadado ao atraso apenas para preservar as características bucólicas que lhe são atribuídas, pois os cidadãos campesinos também têm o direito a uma vida com mais conforto.

A facilidade de acesso aos centros urbanos próximos - para os moradores da vila, principalmente à cidade de Ponta Grossa - e aos meios de comunicação estimula a criação de desejos e necessidades, e causa o contato com as formas de vida urbanas e com as modernidades, desencadeando novas formas de agir e pensar aos moradores da vila. Essas ações que ocorrem com os sujeitos vão gradativamente moldando novos hábitos, novos significados, dando essa característica dialética à cultura e àidentidade dos moradores de vila, a qual também expressa e é resultado dessa nova configuração entre cidade e campo, entre rural e urbano.

\section{CONSIDERAÇÕES FINAIS}

A aproximação entre cidade e campo tem se intensificado. As características do rural e do urbano vão se modificando, como também os sujeitos que vivem nesses espaços. O indivíduo tem seu cotidiano alterado, o que éreflexo das mudanças nos seus hábitos, que podem ser modificados ou ainda reafirmados mediantea realidade que ele presencia e vive, influenciada por essa nova dinâmica de aproximação entre os territórios urbano e rural. Com a facilidade decontato com outras realidades, o sujeito é confrontado com uma variedade de identidades e pode assumi-las a qualquer momento, em qualquer circunstância, adaptando-as às suas necessidades.

A relação com novas culturas não representa a desestruturação total de uma cultura, mas sim a possibilidades de mudança, de aculturação. Como sempre está em 
construção, seadequando ao contexto econômico, político, social e histórico, a cultura pode ser modificada, reconstruída ou reafirmada, uma vez que as novidades/mudanças podem ser aceitas ou não, absorvidas totalmente ou parcialmente, ou serem refutadas.

$\mathrm{Na}$ vila do distrito de Guaragi, a proximidade com os centros urbanos e com as mídias acarretou mudanças. Hábitos comuns aos moradores da cidade são constituídos, sobretudo, pelas formas de consumo. Os moradores da vila possuem mercadorias e aparatos tecnológicos que são tidos como típicos dos espaços urbanos, pois esses bens trazem conforto a elese em muitos casos representam melhoria na condição social e financeira dos que os possuem. Pelo fato de os moradores preservarem muitos hábitos e pelas características da paisagem que são tipicamente rurais, a vila tem se tornado espaço de consumo para os moradores da cidade, que lá compram propriedades,buscando vivenciar o sentimento bucólico que a paisagem proporciona -o canto das aves, a tranquilidade, as relações fraternas de vizinhança, as casas com quintais grandes com pomares e hortas, a presença de animais. Ademais, contam ainda com infraestrutura urbana e a proximidade com a cidade.

Mesmo com a globalização, com a intensificação da relação campo-cidade e a inserção de "modernidades" nesses locais, muito do que lhes é característico é preservado, mas também se transformam, resistem às mudanças ou a elas se adaptam. As diferentes realidades são incorporadas, e a vida dos sujeitos que vivem no campo se modifica. A vila reflete, portanto, características mistas que são mantidas -também nas atividades de lazer e religiosas, como os festejos e encontros para conversar com rodadas de chimarrão. Assim se constrói a rotina, sobre a vivência diária dos sujeitos, encontrando oportunidades e limitações, moldando a identidade vinculada ao espaço que vivem e às "modernidades" que se instalam gradativamente nesse local.

Para melhor administração de recursos e atendimento da população, é que os municípios criam as subdivisões distritais. Todavia, quando não há conhecimento sobre a realidade local, torna-se difícil cumprir essa tarefa. No caso do distrito de Guaragi, a pouca representatividade na economia municipal é um dos fatores que tornam o espaço opaco para o governo municipal; além disso, a falta de representatividade e organização política dificultam ainda mais a expressão local diante do Poder Público, que desconhece as necessidades dos moradores do lugar. $O$ contexto de um espaço de transição entre urbano e rural dá a ele características únicas que devem ser consideradas para oferecer qualidade de vida à população.

Os centros urbanos são buscados, sobretudo para atender às necessidades básicas que não são supridas na vila como saúde, educação, emprego e lazer. A falta de certas infraestruturas no distrito impede o desenvolvimento técnico e informacional desse lugar, ou ao menos a maior fluidez desses fatores, o que causa a estagnação econômica local. Não obstante, todos os projetos a serem desenvolvidos para a vila devem atender às necessidades de melhoria na qualidade de vida da população e também considerar que certas características locais precisam ser respeitadas, sobretudo aquelas que recebem grande apreço dos moradores, como a típica tranquilidade rural que o local apresenta. Os traços culturais urbanos que chegam à vila associados às características rurais expressas 
nos hábitos e no comportamento da população compõem a dualidade que expressa o atual contexto social e cultural do distrito.

Desse modo, é necessário compreender que a aproximação entre cidade-campo coloca as realidades em rápido movimento, e os sujeitos que habitam esses espaços refletem as características desse contato. Portanto, os recursos culturais locais devem ser percebidos e usados como fatores que podem favorecer o desenvolvimento local, auxiliando na melhoria da qualidade de vida da população.

\section{REFERÊNCIAS}

BAGLI, P. Rural e urbano: harmonia e conflito na cadência da contradição. In: SPOSITO, M.E.B.; WHITACKER, A. M. (Orgs.). Cidade e campo: relações e contradições entre urbano e rural. 2.ed. São Paulo: Expressão Popular, 2010, p.9-31.

BARRETO, V. M. As especificidades no processo de formação histórico-geográfico no distrito de Guaragi - Ponta Grossa (PR). 2011. Dissertação (Mestrado em Gestão do Território) - Programa de Pós-Graduação em Geografia, Universidade Estadual de Ponta Grossa,Ponta Grossa - PR, 2009.

BAUCHROWITZ, L. Caracterização dos distritos de Guaragi e Uvaia: uma contribuição para o planejamento distrital do poder público do município de Ponta Grossa (PR),2009. Trabalho de Conclusão de Curso (Graduação em Bacharelado em Geografia) - Universidade Estadual de Ponta Grossa, Ponta Grossa -PR, 2009.

BERNARDELLI, M. L.F . da Hora. Contribuição ao debate sobre o urbano e o rural. In: SPOSITO, Maria Encarnação Beltrão; WHITACKER, A.M.(Orgs.). Cidade e Campo: relações e contradições entre urbano e rural. 2.ed. São Paulo: Expressão Popular, 2010, p.33-52.

CARNEIRO, M. J. Ruralidade: novas identidades em construção. Estudos Sociedade e Agricultura, Rio de Janeiro, n. 11, p. 53-75, out.1998. Disponível em: <http://r1.ufrrj.br/esa/index. php?cA=db\&aI=120\&vT=da\&vA=281>. Acesso em: 18 jun. 2011.

CLAVAL, P. A Geografia cultural. 3.ed. Florianópolis: UFSC, 2007.

CORREAA, R. L.: A Geografia cultural e o urbano. In: CORREAA, R.L.; ROSENDAHL, Zeny. Introdução a Geografia Cultural. Rio de janeiro: Bertrand Brasil, 2003. p. 167-186.

CUCHE, D. A noção de cultura nas ciências sociais. Lisboa: Fim de Século, 1999.

ENDLICH, Â.M. Perspectivas sobre o urbano e o Rural. In: SPOSITO, M.E.B.; WHITACKER, Arthur Magon (Orgs.). Cidade e campo: relações e contradições entre urbano e rural. 2. ed. São Paulo: Expressão Popular, 2010, p.9-31.

HALL, S. A identidade cultural na pós-modernidade. 11.ed. Rio de Janeiro: DP\&A, 2006.

Instituto Brasileiro de Geografia e Estatística. Banco de dados agregados. Disponível em: http://www. sidra.ibge.gov.br/. Acesso em ago. 2011.

KAISER, B. La renaissance rurale: sociologie des campagnes du monde occidental.Paris: Armand Colin, 1990, 316 p.

MANAIA, M. S.R. A Geografia dos distritos rurais de Paiquerê e Warta, Londrina - Paraná, 2009. Trabalho de Conclusão de Curso (Graduação em Bacharelado em Geografia), Universidade Estadual de Londrina, Londrina - PR, 2009.

MONTES, S. R. Entre o campo e a cidade: as territorialidades do Distrito de Tapuirama (Uberlândia/ MG) - 1975 a 2005, 2006. Dissertação (Mestrado em Geografia: Geografia e Gestão do Território) - Programa de Pós-Graduação em Geografia, Universidade Federal de Uberlândia, Uberlândia -MG, 2006.

PROULX, M. -U. Le rôle des territoiresdans la régulation de l'économie-monde. Québec:Associationdes Aménagistesdu Québec, 1997. 
SANTOS, Milton. A natureza do espaço: Técnica e tempo. Razão e emoção. 4.ed.São Paulo:Edusp, , 2006.

SPOSITO, Maria Encarnação Beltrão; WHITACKER, Arthur Magon (Orgs.). Cidade e campo: relações e contradições entre urbano e rural. 2.ed. São Paulo: Expressão Popular, 2010.

WANDERLEY, Maria de Nazareth Baudel. A emergência de uma nova ruralidade nas sociedades modernas avançadas - o "rural" como espaço singular e ator coletivo. Estudos Sociedade e Agricultura, Rio de Janeiro, n. 15, p. 87-145, out.2000. Disponível em: <http://r1.ufrrj.br/esa/index. php?cA=db\&aI=163\&vT=da\&vA=18>. Acesso em: 1 jun. 2011.

WARNIER, J.P. A mundialização da cultura. Bauru:Edusc, 2000.

WHITACKER, A.M. Cidade imaginada. Cidade concebida. In: SPOSITO, Maria Encarnação Beltrão; WHITACKER, A.M. (Orgs.). Cidade e campo: relações e contradições entre urbano e rural. 2.ed. São Paulo: Expressão Popular, 2010, p. 131-155.

Recebido em 16/10/2012

Aceito para publicação em 05/06/2013 